\title{
Primary Percutaneous Coronary Intervention in Chronic Type A Aortic Dissection
}

\author{
Ahmed Farag, MSc, MRCP ${ }^{*}$, Aneesha Chauhan, BA ${ }^{2}$, Sunita Avinash, MRCP ${ }^{1}$, Chee K Liew, FRCR ${ }^{1,3}$, \\ Jonas Eichhöfer, MRCP, PhD ${ }^{1}$, Anoop Chauhan, MB ChB (Hons), MD, FRCP1 \\ ${ }^{1}$ Lancashire Cardiac Center, Blackpool Victoria Hospital, Blackpool, Lancashire, United Kingdom \\ 2 Department of Medicine, University of Oxford, Oxford, United Kingdom \\ ${ }^{3}$ Radiology Department, Blackpool Victoria Hospital, Blackpool, Lancashire, United Kingdom
}

\begin{abstract}
This case illustrates the complexities of performing a primary percutaneous intervention in a patient with chronic Type A aortic aneurysm and dissection with contraindications for surgical management. We also discuss the significant risk that the patient had to overcome to survive an undiagnosed aortic dissection and an acute ST elevation myocardial infarction.

Copyright $\odot 2016$ Science International Corp.
\end{abstract}

\section{Key Words}

ST elevation - Myocardial infarction - Percutaneous coronary intervention • Chronic aortic dissection

\section{Introduction}

To our knowledge, this is the first report of a primary percutaneous coronary intervention ( $\mathrm{PPCl}$ ) in a patient with chronic Type A aortic aneurysm and dissection. This case illustrates the difficulties encountered and the approaches used to achieve a successful outcome.

\section{Case Presentation}

An 80-year-old male with a background history of hypertension and atrial fibrillation (AF) on warfarin

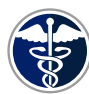

Fax +1 2037853552

E-Mail: aorta@scienceinternational.org

http://aorta.scienceinternational.org

\author{
(c) 2016 AORTA \\ Published by Science International Corp. \\ ISSN 2325-4637 \\ Accessible online at: \\ http://aorta.scienceinternational.org
}

presented via the primary percutaneous coronary intervention ( $\mathrm{PPCl}$ ) pathway complaining of ongoing central chest pain for the past 4 hours. His ECG confirmed an anterior ST elevation myocardial infarction (STEMI).

He was taken to the catheterization laboratory. Access was obtained through the right radial artery (RRA). A right coronary artery (RCA) diagnostic catheter was difficult to maneuver, and nonselective shots showed no significant disease. A Launcher ${ }^{\circledR}$ Medtronic 6-French sheath extra backup (EBU) 3.5 guide was used to engage the left system. This again was difficult to maneuver but identified a proximal left anterior descending artery (LAD) occlusion. We administered 3,000 units of unfractionated heparin. Despite trying different guide catheters and switching to a right femoral artery (RFA) approach, it proved impossible to reach or wire the LAD.

An aortogram through the femoral approach identified a significantly dilated aortic root as well as Type A aortic dissection (Figure 1; see supplemental Video 1 at http://dx.doi.org/10.12945/j.aorta.2015.15. 023.vid.01). Bedside echocardiogram identified a dissection flap with no aortic regurgitation or pericardial effusion. The patient was hemodynamically stable throughout the procedure and did not have any back pain.

After consulting with the cardiothoracic surgeons,

* Corresponding Author:

Ahmed Farag, MSc, MRCP

Lancashire Cardiac Centre

Blackpool Victoria Hospital

Whinney Heys Road, Blackpool, Lancashire FY3 8NR, United Kingdom

Tel: +44 1253 300000, Fax: +44 1253 306873; E-Mail: ahmedkf80@gmail.com 


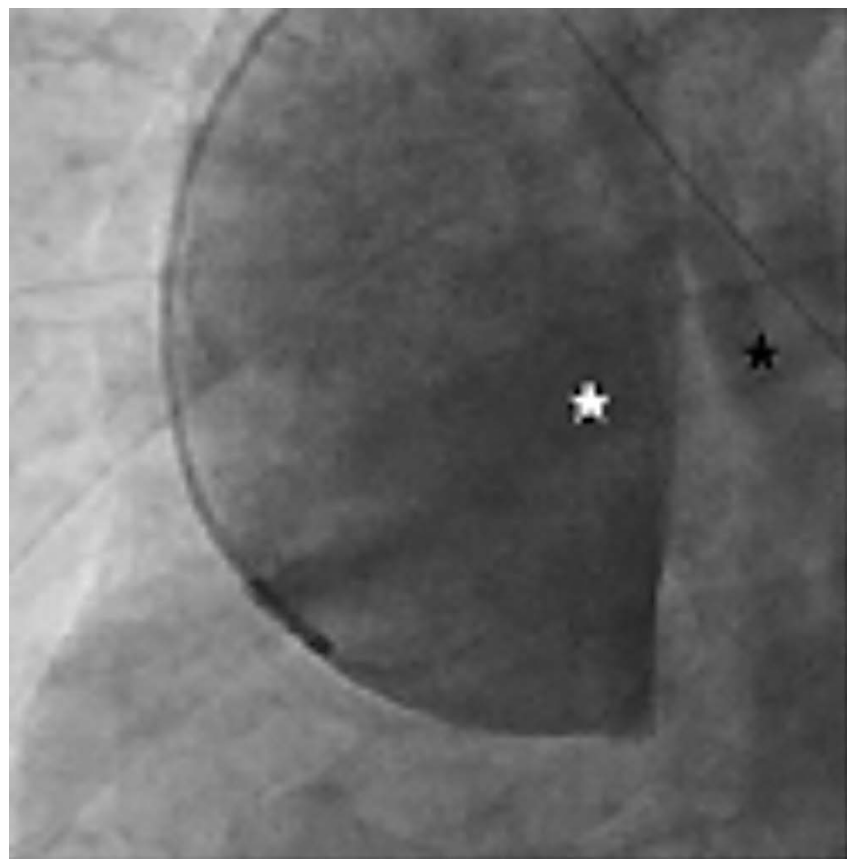

Figure 1. Aortogram showing a Type A aortic root aneurysm and dissection (white star, false lumen; black star, true lumen).

it was felt that the significant aortic root enlargement in addition to the patient's hemodynamic and clinical stability indicated that both the aneurysm and dissection were chronic. The team thought that aortic root surgery would carry an exceptionally high risk due to the concomitant ST elevation myocardial infarction (STEMI) presentation and was therefore not an option. Thrombolysis was discussed, but it was felt that the approach would also carry a very high risk due to his warfarin treatment. Our attention shifted to reattempting $\mathrm{PPCl}$ to open the LAD.

We switched back to the RRA approach. We managed to intubate the left main ostium by extending the reach of a 6-Fr hockey stick guide catheter (Cordis Corp., Miami, FL, USA) with a GuideLiner ${ }^{\oplus}$ catheter (Vascular Solutions Inc., Minneapolis, MN, USA) (Figure 2). Eventually we placed two drug-eluting stents in the LAD, achieving a good final angiographic result.

Subsequent computed tomography (CT) of the aorta showed a 7-cm aortic root aneurysm, as well as a Type $A$ aortic dissection starting at the sinotubular junction involving the proximal right brachiocephalic artery to the origin of right common carotid and terminating distally at the left common iliac artery

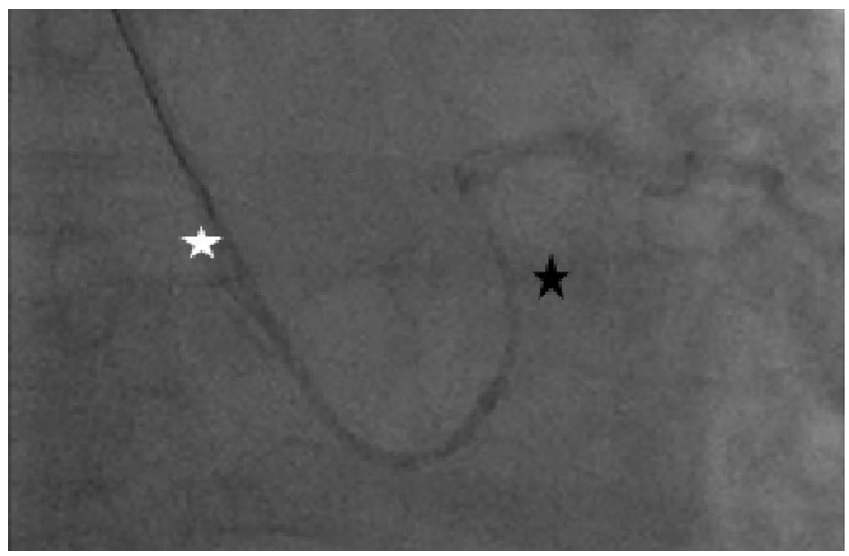

Figure 2. Left main stem engagement using a hockey stick guide catheter (white star) and a guideliner (black star).

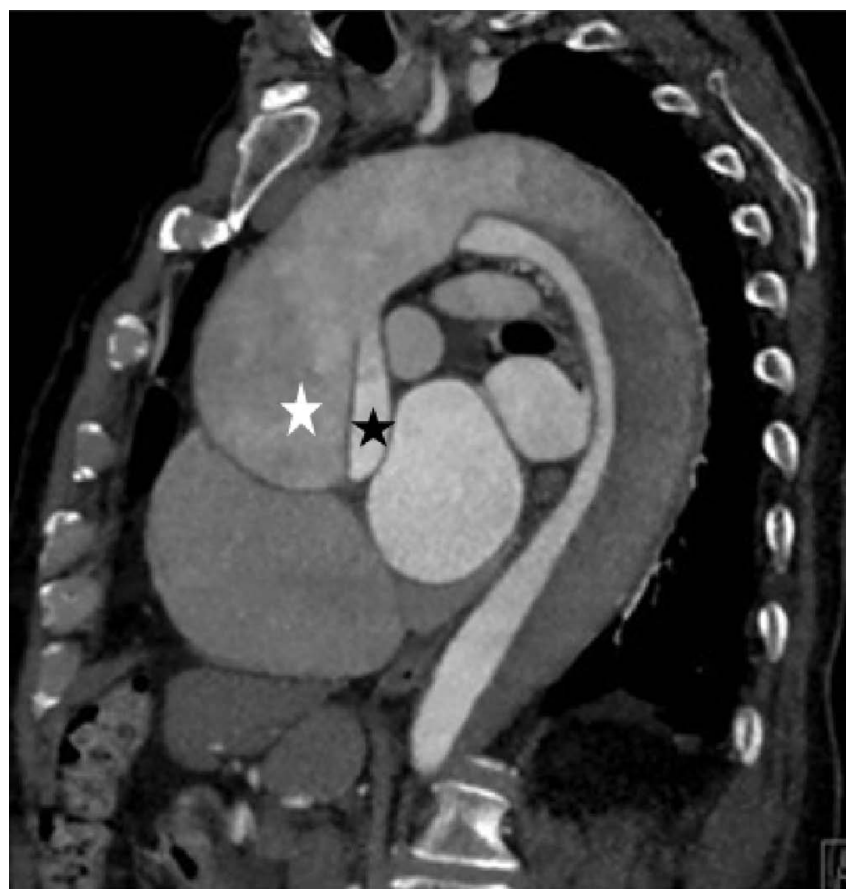

Figure 3. Computed tomography of the aorta showing an aortic root aneurysm and Type A aortic dissection extending into the abdominal aorta (white star, false lumen; black star, true lumen).

(Figure 3). Interestingly there was a large entry zone in the dissection flap starting at the middle of the ascending aorta to the middle of the arch (Figure 4), which is probably where the pigtail catheter entered into the false lumen.

The patient continued to recover and was discharged home safely on dual antiplatelet treatment and aggressive secondary prevention medications. 


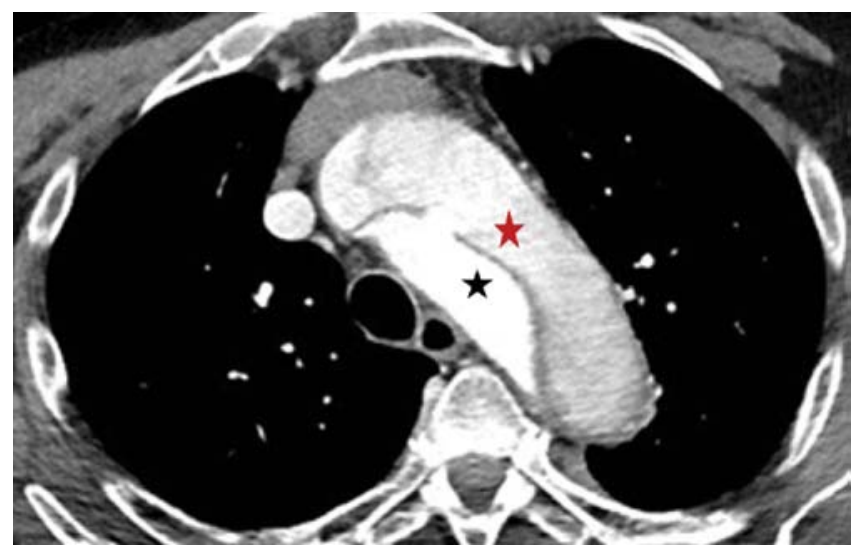

Figure 4. Large entry zone in the dissection flap allowing communication between the true (black star) and false lumens (red star).

His warfarin was stopped. The patient was referred for consideration of cardiac surgery. After discussion, he declined the offer of surgery but agreed to follow-up. At his last appointment, 11 months after his initial presentation, he was asymptomatic, and leading a normal life walking 2-3 miles per day. He elected to continue conservative management rather than surgery, fully understanding the serious nature of his condition.

\section{Discussion}

In healthy adults, the aorta expands by about $0.8 \mathrm{~cm}$ for each decade during the mid-to-late adulthood [1]. In contrast thoracic aortic aneurysms grow, on average, at a rate of $0.10 \mathrm{~cm} /$ year, with larger aortas growing faster $[2,3]$. A thoracic aneurysm measuring over $6 \mathrm{~cm}$ carries annual risks of rupture, dissection, and death of $3.6 \%, 3.7 \%$, and $10.8 \%$, respectively [4]. In patients with no elastopathy, current guidelines recommend aortic root surgery for aneurysms measuring $\geq 55 \mathrm{~mm}[5]$.

Acute Type A aortic dissection is a surgical emergency, and $21 \%$ of patients die before hospital admission
[6]. The mortality rate for untreated patients is $1 \%$ to $2 \%$ per hour soon after symptom onset and $50 \%$ by 1 month [7, 8]. Less than $10 \%$ of untreated patients with proximal aortic dissections live for 1 year, and almost all patients die within 10 years [6].

Not only did our patient beat these odds, he also survived an acute STEMI. He was on long-term warfarin therapy for his chronic AF, and thrombolysis treatment would have carried an increased risk in this setting. Fortunately, we were able to perform a PPCI and achieve a successful outcome in this very challenging situation. To our knowledge, this is the first case report of $\mathrm{PPCl}$ in a patient presenting with unexpected chronic Type A aortic aneurysm and dissection.

There is a previous report of percutaneous intervention for an acute left main coronary occlusion due to aortic root dissection [9]. However, the patient was already known to have a history of bioprosthetic aortic valve replacement and long-standing aortic root dilation that had been followed conservatively because of high reoperative risk. Although diagnostic angiography was difficult and the patient became hemodynamically unstable, that PPCI procedure itself was not technically difficult as the case described here. Our main challenges included engagement of the left main stem, guide catheter support, and the use of a GuideLiner ${ }^{\circledast}$ catheter to extend the reach of the guide catheter. Fortunately, the patient was hemodynamically stable. This case demonstrates that a percutaneous interventional approach can be successful for rare and complicated patients for whom surgery is not possible.

\section{Conflict of Interest}

The authors have no conflict of interest relevant to this publication.

\section{Comment on this Article or Ask a Question}

\section{References}

1. Vriz O, Driussi C, Bettio M, Ferrara F, D'Andrea A, Bossone E. Aortic root dimensions and stiffness in healthy subjects. Am J Cardiol. 2013;112:1224-1229. DOI: 10.1016/j. amjcard.2013.05.068

2. Davies RR, Goldstein LJ, Coady MA, Tittle SL, Rizzo JA, Kopf GS, et al. Yearly rup- ture or dissection rates for thoracic aortic aneurysms: simple prediction based on size. Ann Thorac Surg. 2002;73:17-28. DOI: 10.1016/S0003-4975(01)03236-2

3. Elefteriades J. Thoracic aortic aneurysm: current approach to surgical timing. ACC Curr J Rev. 2002;11:82-88. DOI: 10.1016/

\section{S1062-1458(02)00596-2}

4. Elefteriades JA, Farkas EA. Thoracic Aortic Aneurysm: Clinically Pertinent Controversies and Uncertainties. J Am Coll Cardiol. 2010; 55:841-857. DOI: 10.1016/j.jacc.2009. 08.084

5. Erbel R, Aboyans V, Boileau C, Bossone E, 
Barolomeo RD, Eggebrecht $\mathrm{H}$, et al. ESC Guidelines on the diagnosis and treatment of aortic diseases: Document covering acute and chronic aortic disease of the thoracic and abdominal aorta of the adult. The Task Force for the Diagnosis and Treatment of Aortic Diseases of the European Society of Cardiology (ESC). Eur Heart J. 2014;35:2873-2926. DOI: 10.1093/eurheartj/ehu281

6. Mészráos I, Mórocz J, Szlávi J, Schmidt J, Tornóci L, Nagy L, et al. Epidemiology and clinicopathology of aortic dissection.
Chest. 2000;117:1271-1278. DOI: 10.1378/ chest.117.5.1271

7. Hagan PG, Nienaber CA, Isselbacher EM, Bruckman D, Karavite DJ, Russman PL, et al. The international registry of acute aortic dissection (IRAD): new insights into an old disease. JAMA. 2000;283:897-903. DOI: 10.1001/ jama.283.7.897

8. Nienaber CA, Eagle KA. Aortic dissection: new frontiers in diagnosis and management. Circulation. 2003;108:628-635. DOI: 10.1161/01.CIR.0000087009.16755.E4

9. Ravandi A, Penny WF. Percutaneous in- tervention of an acute left main coronary occlusion due to dissection of the aortic root. JACC Cardiovasc Interv. 2011;4: 713-715. DOI: 10.1016/j.jcin.2010.12.017

Cite this article as: Farag $A$, Chauhan $A$, Avinash S, Liew CK, Eichhöfer J, Chauhan A. Primary Percutaneous Coronary Intervention in Chronic Type A Aortic Dissection. AORTA (Stamford) 2016;4(2): 68-71. DOI: http://dx.doi.org/10.12945/j. aorta.2015.15.023 